\title{
PEMBERDAYAAN MASYARAKAT MELALUI PENGELOLAAN SAMPAH RUMAH TANGGA DI DESA CIMANGGU SATU
}

\author{
Andi Asnifatima ${ }^{1}$, Aldino M. Irfan, Kishi Afifa Putri ${ }^{2}$ \\ asni@uika-bogor.ac.id \\ Dosen Fakultas Ilmu Kesehatan ${ }^{1}$, Mahasiswa KKN Kelompok 27 Tahun $2018^{2}$
}

\begin{abstract}
ABSTRAK
Sampah sudah menjadi masalah klasik pada setiap lingkungan, baik di kota maupun di desa. Kurang nya pengetahuan dan kepedulian masyarakat terhadap lingkungan adalah salah satu penyebab terjadinya penumpukan sampah. Pengadaan penyuluhan tentang bagaimana mengelola sampah bertujuan agar masyarakat sadar akan bahaya sampah bagi kesehatan dan mengetahui cara mengelola sampah supaya menjadi sesuatu yang berguna. Metode yang digunakan dalam kegiatan ini adalah metode survey ke Desa Cimanggu Satu. Melalui kegiatan penyuluhan serta workshop membuat komposter mini dan membuat tempat sampah dari botol bekas yang dihadiri oleh 47 orang mampu mengurangi penumpukan sampah organik dan sampah anorganik. Hasil dari evaluasi setelah kegiatan selesai adalah prilaku masyarakat kini sudah lebih peduli terhadap lingkungan dan kesehatan, dilihat sudah jarang sekali sampahsampah berserakan disekitar tempat tinggal.
\end{abstract}

Kata Kunci : pengelolaan sampah, sampah organik, sampah anorganik

\section{PENDAHULUAN}

Desa Cimanggu Satu merupakan sebuah Desa yang terletak di Kecamatan Cibungbulang Kabupaten Bogor, dengan luas wilayah $170 \mathrm{Ha}$, diatas permukaan laut 240 dpml dan tinggi curah hujan $236 \mathrm{~mm} 3$, suhu rata-rata $20 \mathrm{dc}$ s/d 32 dc yang terbagi dalam 4 (Empat) Dusun, 9 (Sembilan) Rukun Warga (RW) dan 32 (Tiga Puluh Dua) Rukun Tetangga (RT). Berikut detail geografis Desa Cimanggu Satu, Cibungbulang yang menjadi sasaran $\mathrm{KKN}$ UIKA 2018:
Batas Wilayah

\begin{tabular}{|c|l|l|}
\hline No. & Arah & Berbatasan \\
\hline 1. & Utara & $\begin{array}{l}\text { Desa Cijujung } \\
\text { Kolot }\end{array}$ \\
\hline 2. & Timur & $\begin{array}{l}\text { Desa Cimanggu } \\
\text { Dua }\end{array}$ \\
\hline 3. & Selatan & $\begin{array}{l}\text { Desa Cimanggu } \\
\text { Dua }\end{array}$ \\
\hline 4. & Barat & \\
\hline
\end{tabular}


Kondisi Masyarakat

\begin{tabular}{|l|l|}
\hline Laki-laki & 4.945 orang \\
\hline Perempuan & 4.571 orang \\
\hline
\end{tabular}

\section{Pendidikan}

\begin{tabular}{|l|l|l|}
\hline No. & $\begin{array}{l}\text { Tingkat } \\
\text { Pendidikan }\end{array}$ & Jumlah \\
\hline 1. & Tamat TK & 300 orang \\
\hline 2 & Tamat SD & 1.622 orang \\
\hline 3 & Tamat SLTP & 1.812 orang \\
\hline 4 & Tamat SLTA & 1.627 orang \\
\hline 5 & Tamat Diploma & 21 orang \\
\hline 6 & Sarjana & 31 orang \\
\hline
\end{tabular}

Jenis Mata Pencarian

\begin{tabular}{|l|l|r|}
\hline \multicolumn{3}{|l|}{ JENIS PEKERJAAN } \\
\hline Petani & $:$ & 217 Orang \\
\hline Buruh Tani & $:$ & 465 Orang \\
\hline Pegawai Negeri Sipil & $:$ & 24 Orang \\
\hline $\begin{array}{l}\text { Pengrajin Industri } \\
\text { Perumahan }\end{array}$ & $:$ & 21 Orang \\
\hline Pedagang Keliling & $:$ & 83 Orang \\
\hline Montir & $:$ & 22 Orang \\
\hline Dokter Swasta & $:$ & 2 Orang \\
\hline Bidan Swasta & $:$ & 4 Orang \\
\hline Perawat Swasta & $:$ & 3 Orang \\
\hline $\begin{array}{l}\text { Pembantu Rumah } \\
\text { Tangga }\end{array}$ & $:$ & 15 Orang \\
\hline TNI & $:$ & 6 Orang \\
\hline POLRI & $:$ & 1 Orang \\
\hline $\begin{array}{l}\text { Pensiunan } \\
\text { PNS/TNI/POLRI }\end{array}$ & $:$ & 9 Orang \\
\hline $\begin{array}{l}\text { Dukun Kampung } \\
\text { Terlatih }\end{array}$ & $:$ & 3 Orang \\
\hline Dosen Swasta & $:$ & 2 Orang \\
\hline $\begin{array}{l}\text { Karyawan Perusahan } \\
\text { Swasta }\end{array}$ & $:$ & 531 Orang \\
\hline $\begin{array}{l}\text { Karyawan Perusahan } \\
\text { Pemerintah }\end{array}$ & $:$ & 12 Orang \\
\hline
\end{tabular}

\begin{tabular}{|l|l|r|}
\hline $\begin{array}{l}\text { Karyawan } \\
\text { Perusahan } \\
\text { Pemerintah }\end{array}$ & $:$ & 12 Orang \\
\hline Lain-Lain & $:$ & 8096 Orang \\
\hline Jumlah & $:$ & 9516 Orang \\
\hline
\end{tabular}

Sebagian besar penduduk Desa Cimanggu Satu bermata pencaharian sebagai buruh tani dan berkebun, yang hasilnya dijual di pasar-pasar terutama di Jakarta. Penduduk menjual hasil tani dan kebun ke pasar yang berada di Jakarta dan di distribusikan ke tempat-tempat lain serta dijual ke warung-warung terdekat.

Secara umum kondisi masyarakat Desa Cimanggu Satu, Kp. Jatake RW 06 yang telah kami observasi, bahwa masyarakat Kampung Jatake RT 01 / RW 06 Desa Cimanggu Satu cenderung mudah bersosialisasi dan menerima pendatang dengan sangat terbuka. Contohnya seperti kami yang melakukan KKN Tematik Terintegrasi masyarakat menyambut dengan tangan terbuka dan apresiasi yang baik dari masyarakat sekitar. Terlebih lagi kampung Jatake sudah dua kali di datangi oleh kelompok KKN dari Universitas lain, jadi bukan hal yang baru bagi masyarakat Kampung Jatake Cimanggu Satu.

Melihat respon masyarakat yang baik, maka dari itu ketika kami melakukan program kerja kemasyarakatan, masyarakat sekitar pun antusias dengan giatnya mengikuti program-program yang kami selenggarakan yang tentunya untuk kemanfaatan daerah Kp. Jatake RT 01 RW 06 dan sekitarnya. Jadi dapat kami ambil kesimpulan bahwasanya kondisi Masyarakat Kp. Jatake RT 01 RW 06 Desa Cimanggu Satu terlihat baik, bersahabat dan menerima orang-orang pendatang dengan tangan terbuka tanpa adanya konflik dari berbagai pihak. Perumusan 
rencana starategis dalam pengembangan Desa Bojong Sempu yang akan kami lakukan adalah dengan menggunakan analisis SWOT (Strenght, Weakness, Opportunities, dan Threats) terhadap desa. Oleh karena itu kami mencoba menganalisis hal tersebut yakni:

Strength (Kekuatan)

Berdasarkan pengamatan dan inventarisasi kondisi dan potensi Desa Cimanggu Satu, maka dapat diidentifikasikan beberapa faktor yang menjadi kekuatan internal sebagai berikut :

a. Desa Cimanggu Satu memiliki potensi sumber daya alam yang dapat dimanfaatkan untuk memenuhi kebutuhan hidup masyarakat desa. Misalnya lahan persawahan dan perkebunan yang luas.

b. Memiliki lahan untuk dimanfaatkan sebagai lahan perikanan.

c. Lingkungan yang aman dan kondusif dapat mendukung proses pembangunan masyarakat yang terarah.

d. Aksesbilitas internal dan eksternal desa tinggi.

\section{Weakness (Kelemahan)}

Selain memiliki berbagai kelebihan, sebuah desa pasti memiliki kelemahan. Dari hasil identifikasi diperoleh kelemahan Desa Cimanggu Satu, diantaranya :

a. Minimnya tempat pembuangan sampah sementara, sehingga sampah menjadi permasalahan tersendiri dan terbesar serta dapat dilihat dimana-mana.

b. Kualitas air sungai salah satu air baku sudah tercemar oleh limbah rumah tangga.

c. Desa Cimanggu Satu pada umumnya tidak mempunyai jaringan drainase, sehingga sering terjadi banjir sesaat pada saat musim hujan. d. Masih banyak masyarakat yang menggunakan sungai atau koya sebagai media untuk air besar.

e. Masih banyak masyarakat yang tidak mempunyai MCK sendiri.

Opportunities (peluang/kesempatan)

Selain mengidentifikasi faktor internal berupa kelemahan dan kelebihan, pihak desa juga harus mampu menangkap peluang dan ancaman yang datang dari lingkungan eksternal. Adapun yang dapat diidentifikasi antara lain:

a. Permintaan akan produksi pertanian dibutuhkan oleh masyarakat di sekitar desa Cimanggu Satu sehingga masyarakat Desa Cimanggu Satu dapat lebih giat lagi dalam memproduksi hasil tani dan kebun.

b. Tingginya permintaan akan pupuk kandang dan kompos untuk pengembangan kegiatan pertanian.

c. Tingginya permintaan akan sayuran dan beras organic.

Threats (Ancaman )

Hasil identifikasi ancaman untuk Desa Cimanggu Satu antara lain:

a. Competitive produksi pertanian dengan wilayah lain sehingga membutuhkan produksi yang lebih ekstra dan meminimalisir kegagalan dalam produksi.

b. Competitive produksi peternakan dengan wilayah lain.

\section{Latar Belakang}

Sampah adalah sisa kegiatan seharihari manusia dan/atau dari proses alam yang berbentuk padat (Suyoto, 2008). Sampah terbagi menjadi dua, yaitu sampah Organik dan sampah Non Organik. Sampah organik adalah sisa buangan yang berasal dari makhluk hidup baik manusia, hewan 
maupun tumbuhan dan sifatnya yang mudah membusuk. Bakteri merupakan agen yang sangat penting keberadaannya karena perannya sebagai pengurai alami, Sampah ini sangat ramah lingkungan karena memang berasal dari makhluk hidup sehingga jika kita berhadapan dengan Sampah organik tidak perlu bahan kimia, karena nantinya dia akan terurai sendiri. Sedangkan sampah Non Organik adalah segala sisa manusia yang sulit diurai kembali oleh bakteri atau memerlukan waktu yang cukup lama untuk penguraiannya hingga ratusan tahun. Sampah ini dihasilkan dari berbagai macam prosesdan tidak akan bisa terurai oleh bakteri secara alami. Laju produksi sampah terus meningkat, tidak saja sejajar dengan laju pertumbuhan penduduk tetapi juga sejalan dengan meningkatnya pola konsumsi masyarakat. Di sisi lain kapasitas penanganan sampah yang dilakukan masyarakat maupun pemerintah daerah belum optimal. Sampah yang tidak dikelola dengan baik akan berpengaruh terhadap lingkungan dan kesehatan masyarakat sekitarnya.

Di Indonesia, sekitar 56\% sampah dikelola oleh pemerintah. Sisanya dikelola dengan cara dibakar sebesar $35 \%$, dikubur $7,5 \%$, dikompos $1,6 \%$, dan dengan cara lain $15,9 \%$. Apabila sampah dapat ditangani dengan lebih baik dan profesional, kondisi lingkungan akan menjadi lebih bersih. Pembinaan dengan meningkatkan peran serta masyarakat juga diperlukan agar mereka tidak lagi membuang sampah sembarangan seperti di sungai, kolam atau parit untuk mengeliminasi menumpuknya timbunan sampah.

Desa Cimanggu Satu merupakan desa yang terletak di Kecamatan Cibungbulang Kabupaten Bogor. Desa ini terbilang padat penduduknya, terdapat 9516 orang yang terdaftar dan tinggal di Desa Cimanggu Satu. Hal ini membuat produksi sampah semakin banyak. Kondisi lingkungan yang padat penduduk membuat sampah bertebaran dimana-mana, terlebih lagi belum adanya TPS (Tempat Pembuangan Sementara) dan tidak adanya TPA (Tempat Pembuangan Akhir) yang masih direncanakan oleh pihak desa dan baru akan direalisasikan tahun 2019

membuat tempat pembuangan sampah organik dan Non organik oleh warga bertebaran di sekitar rumah penduduk dan bahkan di pinggir jalan raya sehingga mengganggu keindahan dan kebersihan Desa Cimanggu Satu. Sampah menjadi masalah terbesar warga Cimanggu Satu, karena masyarakat yang masih berpikir dengan pola lama bahwa kali atau sungai adalah tempat pembuangan sampah, dan sampah harus dibakar sepenuhnya, mengakibatkan tidak adanya pengelolaan sampah dan membuat lingkungan tercemar.

Pencemaran lingkungan yang semakin meningkat disebabkan oleh berbagai hal, seperti bertambahnya populasi manusia yang mengakibatkan meningkatnya jumlah sampah yang dibuang. Hal ini diperburuk dengan kurang memadainya tempat dan lokasi pembuangan sampah, kurangnya kesadaran dan kemauan masyarakat dalam mengelola dan membuang sampah, masih kurangnya pemahaman masyarakat tentang manfaat sampah, serta keengganan masyarakat memanfaatkan kembali sampah, karena sampah dianggap sebagai sesuatu yang kotor dan harus dibuang ataupun gengsi. Berbagai hal tersebut menyebabkan menurunnya kualitas lingkungan yang berdampak negatif bagi masyarakat.

Sampah sangat berbahaya bagi kesehatan manusia dan lingkungan sekitar. Oleh karena itu, sampah haruslah diolah 
atau di daur ulang dengan baik agar tidak mencemari lingkungan dan mengganggu kesehatan manusia. Sampah yang selama ini kita buang begitu saja, ternyata masih dapat diolah kembali antara lain dalam bentuk kerajinan yang bernilai ekonomi, bercita rasa seni dan unik. Secara umum pengelolaan sampah dilakukan dalam tiga tahap kegiatan, yaitu : pengumpulan, pengangkutan, dan pembuangan akhir/pengolahan. Pada tahap pembuangan akhir/pengolahan, sampah akan mengalami proses-proses tertentu, baik secara fisik, kimiawi, maupun biologis.

Kegiatan pengelolaan sampah akan melibatkan penggunaan dan pemanfaatan berbagai prasarana dan sarana sampah yang meliputi pewadahan, pengumpulan, pemindahan, pengangkutan, pengolahan maupun pembuangan akhir. Masalah sampah berkaitan erat dengan dengan pola hidup serta budaya masyarakat itu sendiri. Oleh karena itu penanggulangan sampah bukan hanya urusan pemerintah semata akan tetapi penanganannya membutuhkan partisipasi masyarakat secara luas. Jumlah sampah ini setiap tahun terus meningkat sejalan dan seiring meningkatnya jumlah penduduk dan kualitas kehidupan masyarakat atau manusianya dan disertai juga kemajuan ilmu pengetahuan teknologi yang menghasilkan pula pergeseran pola hidup masyarakat yang cenderung konsumtif. 


\section{METODOLOGI}

\section{Tahap Pelaksanaan}

Tahap Pelaksanaan untuk kegiatan ini sebagaimana pada bagan sebagai berikut:
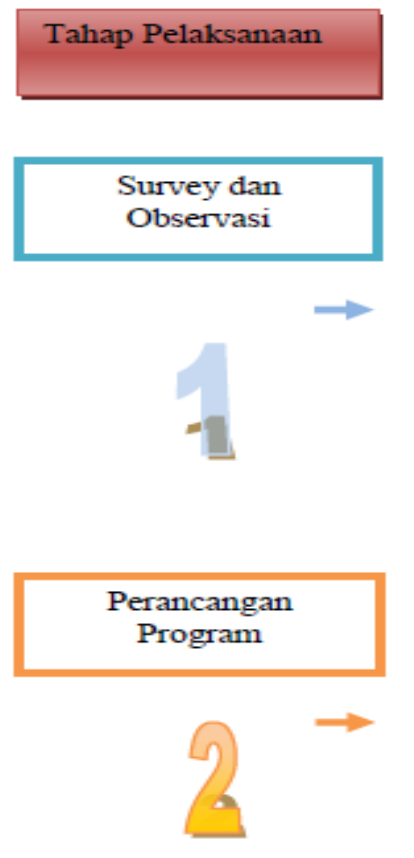
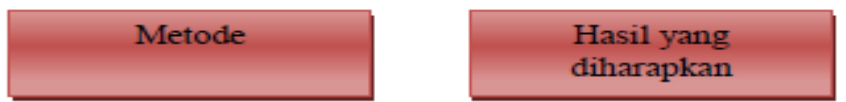

\section{Dengan melihat}

langsung lokasi

sasaran atau kegiatan

yang dilaksanakan

dilokasi sasaran dan

mengajukan

beberapa pertanyaan

terhadap

narasumber, yaitu

Kepala Desa

setempat.

\section{Dengan}

merencanakan,

menyusun dan

mencatat semua

kegiatan yang

berhubungan dengan

masalah yang

dihadapi.

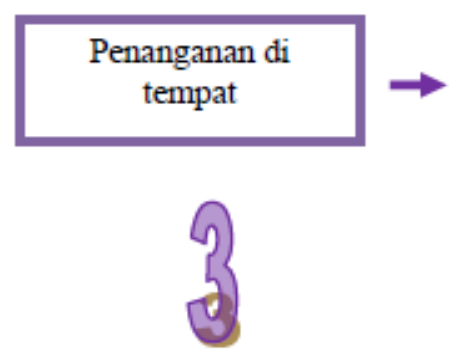

Pengolahan sampah yang telah dipilah

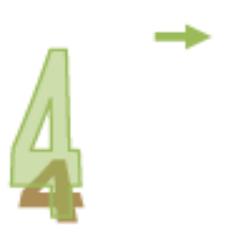

Agar mengetahui permasalahan yang dihadapi Desa setempat dengan sejelas-jelasnya.

Bisa menanggulangi sekaligus mencegah masalah yang sering terjadi di Desa setempa

Timbulnya
kesadaran warga
akan sampah seperti
botol aqua dan
ember bekas bisa
dimanfaatkan/di
daur ulang untuk
dijadikan barang
yang sangat berguna
untuk kehidupan
masyarakat di Desa.

masyarakat di Desa.

Timbulnya

kesadaran warga

akan sampah seperti

botol aqua dan

emer bekas bisa rumah warga.

Dengan pemilahan

(shorting),

pemanfaatan

kembali (reuse), dan

daur ulang (recycle).

Memilah sampah

yang bisa

dimanfaatkan dan

didaur ulang seperti

botol aqua dan

ember bekas bekas

yang banyak

bertebaran di rumah$$
\text { warga. }
$$

\begin{tabular}{|l|l}
$\begin{array}{l}\text { Pembuatan } \\
\text { komposter mini dan } \\
\text { tempat sampah dari } \\
\text { botol aqua }\end{array}$ & $\begin{array}{l}\text { Agar bisa } \\
\text { mengurangi sampah } \\
\text { rumah tangga dan } \\
\text { meningkatkan } \\
\text { kesadaran warga } \\
\text { akan banyaknya } \\
\text { manfaat dan } \\
\text { kegunaan sampah } \\
\text { organik maupun non } \\
\text { organik untuk } \\
\text { kehidupan sehari- } \\
\text { hari. }\end{array}$ \\
\hline
\end{tabular}




\begin{tabular}{|c|c|c|c|c|c|}
\hline \multirow{2}{*}{ No } & \multirow{2}{*}{ KEGIATAN } & \multicolumn{4}{|c|}{ MINGGU } \\
\hline & & 1 & 2 & 3 & 4 \\
\hline 1 & Survey rencana pengolahan & & & & \\
\hline 2 & Penyusunan Rencana Kegiatan & & & & \\
\hline 3 & Sosialisasi Rencana Kegiatan & & & & \\
\hline 4 & Pembuatan Komposter mini & & & & \\
\hline 5 & Pembuatan Tong Sampah dari Botol & & & & \\
\hline 6 & Penyebaran Undangan Warga untuk Kegiatan & & & & \\
\hline 7 & Pelaksanaan Workshop Pengelolaan Sampah & & & & \\
\hline 8 & Evaluasi Program. & & & & \\
\hline
\end{tabular}

\section{Metode Pendekatan}

Pendekatan yang digunakan dalam kegiatan ini adalah:

a. Pendekatan organisasi, yaitu pendekatan dimana dalam kegiatan ini dihadiri oleh seluruh anggota PKK

b. Pendekatan sosial, yaitu dengan mengintegrasikan diri (meleburkan diri) ke berbagai kegiatan masyarakat di Desa Cimanggu Satu khususnya ke sasaran peserta workshop pengelolaan sampah rumah tangga. Pendekatan sosial juga dilakukan saat sesudah perencanaan kegiatan, pelaksanaan kegiatan, maupun evaluasi kegiatan.

\section{Partisipasi Peserta dalam Pelaksanaan Program}

a. Peserta seperti tokoh masyarakat, kader posyandu, anggota PKK hadir dalam kegiatan yang dilaksanakan oleh Mahasiswa KKN Ibn Khaldun kelompok 27 salah satunya workshop pengelolaan sampah.

b. Peserta membantu mengumpulkan botol bekas untuk praktek pembuatan tempat sampah daur ulang

\section{Langkah Evaluasi}

Evaluasi yang dilakukan terdiri dari:

a. Evaluasi Proses yaitu selama kegiatan berlangsung peserta kegiatan workshop cukup antusias. Dari awal peserta datang mereka sudah membawa botol bekas yang telah diwajibkan membawanya. Peserta juga terlihat semangat saat mengisi kuesioner. Peserta juga cukup memperhatikan pemateri.

b. Evaluasi Hasil, yang dilakukan setelah kegiatan workshop. Setelah 3 hari kegiatan workshop berlangsung, kami mengamati peserta. Dari hasil pengamatan, kami melihat peserta mulai mencoba - coba membuat tong sampah dengan mengajak tetangganya. Selain itu juga para ibu rumah tangga yang mengikuti kegiatan workshop mengumpulkan sampah dapur untuk pembuatan komposter mini. Dan juga kami melihat peserta sudah meminimalisir plastik menggantinya dengan goodie bag.

c. Evaluasi Dampak dalam kegiatan workshop pengelolaan sampah di Desa Cimanggu Satu sebagai berikut :

1. Bertambahnya wawasan peserta workshop yang terdiri dari tokoh masyarakat, kader posyandu, dan Anggota PKK.

2. Adanya pengaplikasian pada penyampaian kegiatan workshop seperti meminimalisir pengunaan plastic, memanfaatkan botol untuk membuat tong sampah, memanfaatkan sampah dapur.

3. Bertambahnya antusias peserta dalam menuntut ilmu. 
4. Tali silaturahim antara mahasiswa KKN dengan peserta workshop yang terdiri dari tokoh masyarakat, kader posyandu, dan Anggota PKK.

\section{REALISASI KEGIATAN}

Kegiatan KKN kelompok 27 yang sudah terealisasi adalah workshop pengelolaan sampah. Workshop pengelolaan sampah ini dilaksanakan pada kamis tanggal 30 Agustus 2018. Bertempat di Aula Desa Cimanggu Satu Kecamatan Cibunbulang. Acara ini dihadiri oleh 56 peserta yang terdiri dari ibu-ibu PKK maupun posyandu, RT dan RW sekitaran Desa serta warga Desa Cimanggu Satu. Adapun pembicara pada acara ini adalah ibu Andi Asnifatima, S.K.M., M.Kes. yang merupakan dosen tetap dari Program Studi Kesehatan Masyarakat, Fakultas Ilmu Kesehatan, Universitas Ibn Khaldun Bogor, dengan materi workshop sebagai berikut : 1) Pengantar Tentang Sampah, 2) Mengolah Sampah Organik, 3) Mengolah Sampah Anorganik.

Sebelum acara ini dimulai kami memberikan quisioner mengenai sampah, yang bertujuan untuk mengukur pengetahuan peserta workshop seputar sampah.
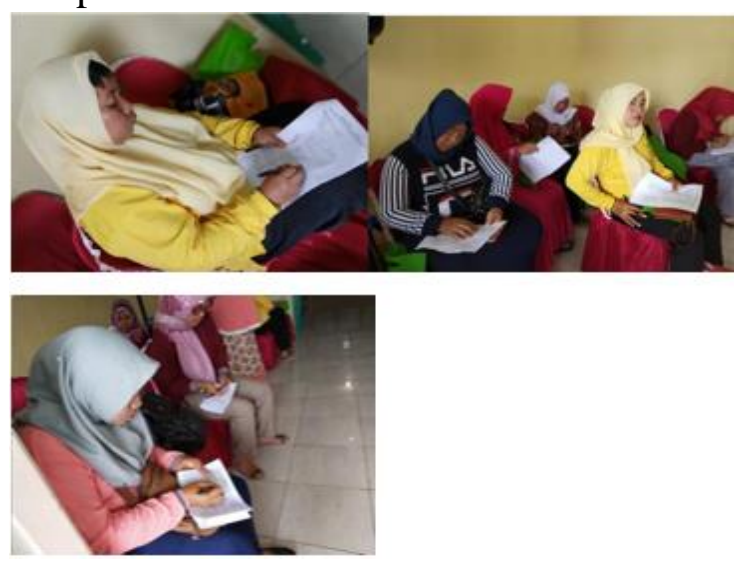

(pengisian quisioner sebelum acara dimulai)
Setelah itu acara dimulai pada pukul 13.30 WIB. Setelah pembacaan materi, narasumber mengadakan praktek pembuatan minikomposter untuk sampah organik atau sampah rumah tangga yang nantinya akan menjadi pupuk setelah diberikan cairan EM4.

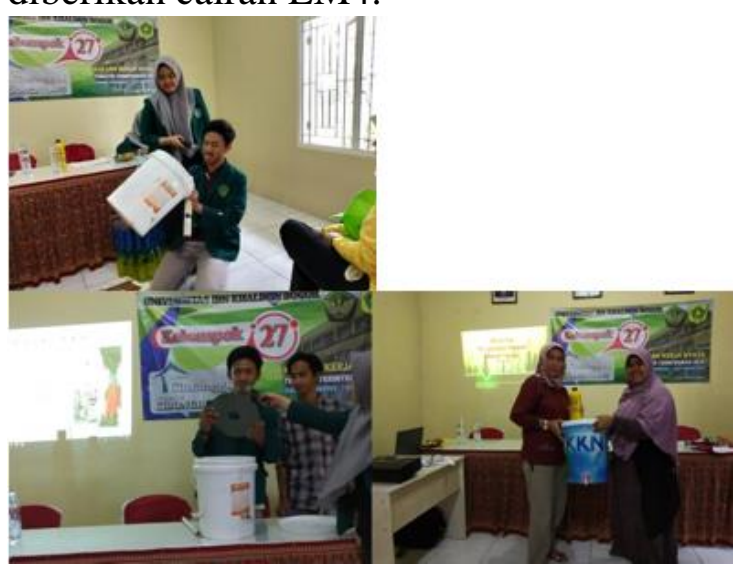

(praktek pembuatan minikomposter)

Dilanjutkan dengan praktek membuat tempat sampah dari botol plastik yang bertujuan untuk memanfaatkan barang bekas menjadi barang bermanfaat serta dapat mengurangi penumpukan sampah yang terjadi di desa Cimanggu Satu.

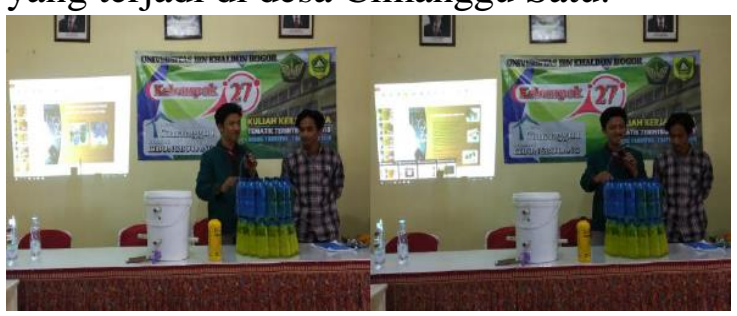

(contoh dari hasil pembuatan tempat sampah dari botol plastik)

Acara selesai pada pukul 16.00 WIB dan di lanjutkan dengan pemberian posttest yang bertujuan untuk mengetahui pemahaman peserta mengenai sampah setelah mengikuti workhop tersebut. 
Dan rincian dana yang dikeluarkan dalam acara ini adalah sebagai berikut :

- Perlengkapan pembuatan komposter mini \& tong sampah : Rp 57.000

- ATK, Print, Fotocopy : Rp 116.000

- Konsumsi : Rp 400.000

- Goodiebag

TOTAL $: \operatorname{Rp} 300.000+$ Rp 873.000

\section{KESIMPULAN}

Permasalahan yang secara umum terjadi adalah masalah pengelolaan sampah atau limbah. Workshop pengelolaan sampah ini dilaksanakan pada tanggal 30 Agustus 2018 bertempat di Aula Desa Cimanggu Satu Kecamatan Cibunbulang, yang diikuti oleh 47peserta.

Kegiatan ini bertujuan agar warga dapat mengubah sampah menjadi material yang memiliki nilai ekonomis (pemanfaatan sampah). Salah satu contohnya yaitu dengan memisahkan sampah organik dan sampah non organik.

Sebelumnya mahasiswa KKN kelompok 27 telah membuat minikomposter untuk sampah organik atau sampah rumah tangga yang nantinya akan menjadi pupuk setelah diberikan cairan EM4. Dan untuk sampah non organik telah dibuatkan salah satu contoh tempat sampah dari daur ulang botol bekas.

\section{SARAN}

Berikut beberapa saran yang dapat kami jabarkan selama program KKN yang berlangsung kurang lebih selama 30 hari di Desa Cimanggu Satu Kecamatan Cibungbulang:

1. Kepada pemerintah daerah untuk lebih memperhatikan masalah kebersihan, terutama masalah sampah. Karena belum adanya tempat pembuangan sampah umum yang bisa menampung sampah-sampah rumah tangga, sehingga masih banyak dijumpai warga warga yang membuang sampah sembarangan, seperti menggantung atau menaruh sampah rumah tangga didepan maupun dihalaman rumah.

2. Untuk mahasiswa hendaknya meningkatkan kesiapan dalam hal fisik, mental, dan penguasaan kegiatan yang akan dilaksanakan selama kegiatan KKN. Agar terhindar dari masalahmasalah terutama kesehatan, dimana selama KKN banyaknya yang jatuh sakit sehingga cukup menghambat jalannya program.

3. Mahasiswa diharapkan lebih kreatif dalam membuat program kerja KKN.

4. Untuk Masyarakat Desa Cimanggu Satu khusunya RT 01/06 diharapkan lebih maju dan mandiri dengan kekayaan desa yang sudah cukup baik, dan tetap mempertahankan prestasi yang telah ada.

5. Dan juga masyarakat Desa Cimanggu Satu khususnya RT 01/06, diharapkan mampu mengambil pelajaran, pengalaman, dan wawasan baru dari apa yang telah KKN laksanakan selama kurang lebih 30 hari. 


\section{REFEREENSI}

Buku panduan LPPM

https://tekoneko.net/sampah-organik-dannon-organik/ 28 April 2017

http://www.pengertianmenurutparaahli.net/ pengertian-sampah-organik-dananorganik-beserta-contohnya/

http://mukti-

aji.blogspot.com/2008/05/sistempengelolaan-sampah-terpadu.html

https://www.youtube.com/watch?v=FDOr $\underline{\text { ma4enac }}$

https://www.youtube.com/watch?v=aWrG UqxwAxU Tobing, I. S. L. . Dampak Sampah terhadap Kesehatan Lingkungan dan Manusia. Makalah pada Lokakarya "Aspek Lingkungan dan Legalitas Pembuangan Sampah serta Sosialisasi Pemanfaatan Sampah Organik sebagai Bahan Baku Pembuatan Kompos" Kerjasama Universitas Nasional dan DIKMENTI DKI, Jakarta. 2005.

Jailan Sahil, dkk. 2016. Sistem Pengelolaan dan Upaya Penanggulangan Sampah Di Kelurahan Dufa-Dufa Kota Ternate. Jurnal BioEdukasi.

Nur Rahmawati Sulistriyono, dkk. 2016. Partisipasi Masyarakat dalam Pengelolaan Sampah di Lingkungan Margaluyu Kelurahan Cicurug. Jurnal Sosial, Volume 5.

Profil Desa Cimanggu Satu
Suyoto, Bagong. 2008. Rumah Tangga Peduli Lingkungan. Prima Media, Jakarta.

Trihadiningrum, Y. MDG's Sebentar Lagi.PT. Kompas Media Nusantara. 2010.

Williamsitama. https://hidupsimpel.com/sampahorganik-dan-non-organik/ 